\title{
A natureza do vínculo na vida humana*
}

\author{
Sheila Daniela Medeiros dos Santos ${ }^{1}$ \\ Universidade de Campinas
}

\section{Resumo}

Este artigo objetiva analisar a origem e as implicações da criação do vínculo na vida humana. Ao retomar algumas concepções teóricas acerca do vínculo, construídas historicamente com base na Psicanálise e na Etologia, 0 texto enfatiza as contribuições significativas e os pontos frágeis apresentados por estes campos do conhecimento. Posteriormente, propõe uma (re)interpretação do fenômeno do vínculo a partir da perspectiva históricocultural em Psicologia. Considerando que a passagem do biológico para 0 cultural se dá através das relações sociais, então, pode-se afirmar que a necessidade de criar vínculos é o ponto de intersecção entre natureza e cultura, o qual leva à sociabilidade humana.

Palavras-chave: Criança; vínculo; perspectiva histórico-cultural; relações sociais.

\begin{abstract}
This article aims to examine the origin and implication of the creation of attachment in the human life. By resuming some theoretical concepts about the attachment, built historically based on Psychoanalysis and Ethology, the text emphasizes the significant contributions and fragile points presented by these fields of knowledge. Later, proposes a reinterpretation of the phenomenon of attachment from the cultural-historical perspective in psychology. In consideration that the transition from the biological to the cultural occurs through social relations, then we can say that the need to create attachments is the point of intersection between nature and culture which leads to human sociability.
\end{abstract}

Keywords: Child; attachment; cultural-historical perspective; social relations.

\footnotetext{
"The nature of attachment in the human life

${ }^{1}$ Endereço para correspondências: Rua Dona Maria Umbelina Couto, 388, ap. 61, Taquaral, Campinas, SP, 13076-011 (sheiladaniela@yahoo.com.br).
} 


\section{HưmANAS}

Desde o início do século XX, a psicologia demonstrou uma preocupação crescente pelo estudo da criança, embora os primeiros trabalhos consolidassem idéias controversas e reducionistas a respeito dela, pelo fato de serem produzidas no âmago de determinadas relações e condições históricas concretas, marcadas por princípios e modelos explicativos distintos: de ordem idealista ou materialista, racionalista ou empiricista, que privilegiavam aspectos orgânicos ou mentais, estruturais ou funcionais.

Desse modo, a disseminação da produção científica no campo da Psicologia Infantil resultou em trabalhos bastante desiguais, que ora atribuíam papel central a fatores biológicos, hereditários ou de maturação (BINET; SIMON, 1929; GESELL, 1992), ora procuravam ater-se a fatores externos, relacionados ao ambiente e à aprendizagem (SKINNER, 1985, 1989).

Nesse embate, surgiram outros trabalhos (VIGOTSKI, 1994, 1995, 2001; WALLON, 1968, 1979, 1995) que baseados em abordagens interacionistas, propunham uma relação entre as condições genéticas da criança e a materialidade concreta do contexto histórico-cultural em que a criança se encontrava desde $o$ início de sua existência.

Todos estes trabalhos chamaram a atenção, cada um a seu modo e a partir de perspectivas teóricas distintas, para a investigação de diversos aspectos referentes ao processo de desenvolvimento da criança. No entanto, devido à diversidade existente quanto aos pressupostos básicos que explicavam tal processo, o conhecimento acumulado nesse campo tornou-se restrito e pouco sistemático pelo fato de não apresentar uma visão que concatenava todas as dimensões (des)conhecidas da infância.

Considerando essa argumentação, é possível observar que até mesmo as grandes correntes do pensamento psicológico, incluindo as de inestimável relevância, como a teoria piagetiana (PIAGET, 1970, 1971, 1975) e a psicanálise (FREUD, 1998, 2002), ora forneciam modelos de análise complexos e contribuições expressivas acerca de alguns aspectos, ora apresentavam pontos frágeis e explicações parciais, por estarem ancoradas em uma visão naturalista que não considerava a natureza histórico-cultural do homem e a mediação semiótica na transposição do plano social para o plano pessoal no processo de constituição da (inter)subjetividade humana.

Nesse cenário, um aspecto de grande importância que apresenta diversos pontos inconsistentes e que, nas palavras de Zazzo (1989), emerge como objeto de reflexão e investigação sistemática no campo do desenvolvimento infantil, refere-se ao vínculo que o bebê estabelece com outro ser humano. 
A natureza do vínculo na vida humana

Sheila Daniela Medeiros dos Santos

Obviamente, não há nada de novo no fato do bebê unir-se à mãe (ou ao seu substituto) após o nascimento. A idéia intrigante e ainda nebulosa não reside nesse fato, mas encontra-se justamente na explicação da origem do vínculo e na problematização das implicações de sua existência na vida humana.

Entretanto, que concepções sobre o vínculo sustentam sua presença na psicologia da infância? Quais estudos contribuíram e/ou contribuem para o significado do vínculo construído historicamente pelas principais correntes psicológicas? Como o vínculo se desenvolve a partir do momento em que é instituído? E qual é o seu papel no processo de desenvolvimento da criança? Estas são algumas questões primordiais que se colocam quando se busca a compreensão cientificamente fundamentada de um dos pontos nodais da psicologia da infância, tal como o vínculo.

A partir de tais considerações, este trabalho procura contribuir para o avanço das discussões a respeito da natureza do vínculo na vida humana, tendo como quadro de referência os pressupostos teórico-metodológicos de Vigotski $(1994 ; 1995$; 1996), Wallon $(1968 ; 1979 ; 1995)$ e Zazzo $(1974 ; 1989)$.

Desse modo, o ponto de partida da investigação que deu origem a este texto, é um conjunto de idéias sustentadas à luz do materialismo histórico e dialético, em particular duas delas: a primeira, é a de que o homem é um ser histórico que, através do trabalho (processo privilegiado nas relações ho$\mathrm{mem} / \mathrm{mundo}$ ), transforma a natureza (realidade objetiva que existe fora $\mathrm{e}$ independentemente da consciência), ao mesmo tempo em que se transforma, o que faz dele, a partir dessa relação com o mundo natural e social, produtor de cultura e produtor de si mesmo. E a segunda, é a de que os fenômenos não podem ser compreendidos isoladamente, mas devem ser considerados do ponto de vista de suas relações, de seu movimento e de sua transformação, já que comportam contradições, paradoxos e conflitos.

Com efeito, discutir certo modo de conceber e elaborar teoricamente a questão do vínculo em uma abordagem da psicologia cujos pontos de ancoragem se situam em premissas pertencentes à matriz marxista, não significa simplesmente a revisão acerca do conhecimento que temos sobre o desenvolvimento da criança, mas significa a síntese de uma profunda transformação em nossas concepções sobre a primeira infância e sobre o desenvolvimento humano. 


\section{HUMANAS}

\section{Algumas teorias sobre o vínculo: breves considerações}

Até meados da década de 1950, predominava apenas um ponto de vista explicitamente formulado sobre a natureza do vínculo. Tanto Freud $(1998,2002)$ e seus seguidores, quanto os teóricos da aprendizagem (DOLLARD; MILLER, 1969; SCHAFFER, 1984; SEARS, 1975) invocaram razões relacionadas ao alimento e ao sexo. Na tentativa de explicarem porque uma criança se ligava à mãe, estes estudiosos supuseram, cada um a partir de sua perspectiva teórica e de sua ambiência histórica, que isso se devia ao fato da criança depender da mãe, como fonte de suas satisfações fisiológicas. Já na tentativa de compreenderem porque os adultos se ligavam uns aos outros, o sexo foi comumente considerado por eles como uma explicação óbvia e suficiente.

Durante muito tempo, sustentou-se a hipótese de que os vínculos desenvolviam-se porque, para satisfazer certos impulsos como de alimentação na infância e de sexo na vida adulta, um indivíduo necessitava de outro ser humano.

Esse pressuposto (tradicional) propunha duas espécies de impulso, os primários e os secundários, sendo que o alimento e o sexo eram classificados como impulsos primários, e a dependência ${ }^{2}$, bem como as outras relações pessoais eram classificadas como impulsos secundários.

Nesse sentido, o termo primário referia-se a uma tendência ou reação que se produzia independentemente, e o termo secundário referia-se ao que era derivado de uma tendência primária, de um sistema primitivo, através de um processo de aprendizagem. Portanto, acreditava-se, até então, que a partir da satisfação das necessidades primárias do recém-nascido seriam criadas e consolidadas, ao longo do tempo, relações que uniam o bebê ao mundo.

Para Freud (1998) a satisfação da necessidade de alimento tinha por objetivo a resolução de uma tensão orgânica: por meio do seio materno a criança saciaria a sua fome, ao mesmo tempo em que encontraria o objeto de seu prazer, a mãe. No sentido freudiano do termo, o impulso libidinal, ou sexual, apoiava-se sobre a função vital de alimentação. No caso, a dependência física geraria pouco a pouco a dependência psíquica, ou seja, as necessidades fisiológicas gerariam a necessidade de outro ser humano.

\footnotetext{
${ }^{2}$ Segundo Freud (2002) o recém-nascido é completamente dependente dos cuidados de um adulto para ter suas necessidades fisiológicas supridas e, por conseguinte, garantir a sua sobrevivência. É desse postulado que deriva o conceito de dependência.
} 
A natureza do vínculo na vida humana

Sheila Daniela Medeiros dos Santos

Em síntese, Freud (2002), através da psicanálise, conduziu a discussão em termos de relações objetais, na qual o objeto de um instinto é definido como "a coisa a respeito da qual ou através da qual o instinto pode alcançar sua finalidade" (FREUD, 1998, p. 122).

A referência ao termo relações objetais nos remete aos trabalhos freudianos sobre a vida pulsional. O conceito de pulsão refere-se a um impulso que objetiva reduzir/suprimir determinado estado de tensão. A redução/supressão dessa tensão constitui o prazer, enquanto que aquilo no qual a pulsão atinge sua finalidade é o objeto.

Freud (1998) na conceituação das pulsões postulou duas categorias: as pulsões de vida ou sexuais, cuja energia dirigida a estabelecer novos vínculos é denominada de libido; e as pulsões de morte, orientadas a eliminar o estado de tensão anterior.

Num sentido amplo, as relações objetais se definem, portanto, como aquelas em que o outro ${ }^{3}$ se constitui como objeto libidinoso do $e u$, o que implica em um investimento libidinoso desse objeto que não é fixo, mas é real, simbólico ou imaginário.

De acordo com Spitz (1996), autor que privilegiou a teoria psicanalítica em suas pesquisas, a construção da relação objetal estabelecida entre mãe e criança, institui o nascimento do ser psicológico, isto é, do ser da relação.

Numa leitura fiel às obras de Freud, Spitz (1996) prioriza o inconsciente e ressalta que as fantasias da mãe a respeito da maternidade e da relação que ela tem com o mundo e com a sua sexualidade, configuram as "atitudes inconscientes formadoras" da díade simbiótica do início da vida do bebê. Nesse processo, ressalta Spitz (1996), ocorrem saltos qualitativos, como o aparecimento do sorriso, que só são possíveis a partir do intercâmbio constante da criança com a mãe (ou o seu substituto).

Nessa perspectiva, a relação mãe-bebê se dá através de uma forma de comunicação expressiva inconsciente (não intencional) em que um gesto ou uma postura da criança traduzem estados interiores, provocando uma reação imediata na mãe (também não intencional). Segundo Spitz(1996), este é um legado da espécie ativo no início da vida até que a linguagem venha a se estabelecer como forma de comunicação dominante $e$ as potencialidades da criança estejam desenvolvidas, para que ela se torne independente de seu ambiente.

${ }^{3} 0$ termo "outro", nesse trabalho, refere-se ao lugar simbólico ocupado pelos inúmeros parceiros das relaç̃oes sociais do ser humano, ao longo de sua história social e pessoal. 


\section{HUMANAs}

Entretanto, de acordo com Zazzo (1974), embora os teóricos das relações objetais (SPITZ, 1996; KLEIN, 1969; WINNICOTT, 1990), com especial destaque a Spitz (1996), que estudou a interação e o problema da separação mãe-filho, e os teóricos da aprendizagem (DOLLARDE MILLER, 1969; SCHAFFER, 1984; SEARS, 1975), com ênfase em Schaffer (1984), que mostrou a maneira pela qual os bebês formam as relações sociais primárias e os mecanismos cognitivos, tivessem reconhecido a imensa importância dos vínculos na vida do homem ${ }^{4}$, é possível notar que tais estudiosos não desenvolveram uma estrutura científica adequada, dentro da qual a criação, a manutenção e o rompimento de tais vínculos pudessem ser entendidos.

Então, conforme Zazzo (1974) bem observou, como as proposições psicanalíticas e aquelas derivadas da teoria da aprendizagem se mostraram insuficientes para explicar a origem do vínculo, no início da década de 1950, houve uma tentativa de preencher essa lacuna pelos etologistas, começando pelo estudo clássico de Lorenz, The Companion in the Bird's World, publicado originalmente em 1935. Esse estudo, por conter experimentos sobre imprinting, ofereceu uma abordagem alternativa e inspirou psicólogos (AINSWORTH, 1963, BOWLBY, 1990) a realizarem pesquisas sobre a temática em macacos rhesus, bem como em seres humanos.

Em um de seus ensaios, Lorenz (1969) ressalta a existência de comportamentos instintivos geneticamente construídos para capacitar os animais a aprender tipos específicos de comportamento que são essenciais para a sobrevivência das espécies. Imprinting é, então, uma dessas formas de comportamento (LORENZ, 1970).

Antes do imprinting se instalar, o filhote tem a capacidade de reconhecer, a partir de componentes inatos, e dentro de sistemas sinaléticos ${ }^{5}$, os tipos de estímulos os quais serão subsequentemente aprendidos. Nessa perspectiva, ações motoras são desencadeadas facilitando o processo de aprendizagem e mantendo proximidade ao objeto de ligação.

\footnotetext{
${ }^{4}$ É inegável o fato de que estes teóricos, ao aprofundarem seus estudos sobre a temática, mesmo apresentando divergências quanto às suas bases epistemológicas, demonstraram haver unanimidade em considerar a importância do vínculo desde os primeiros dias de vida e o efeito prejudicial que a perda desse vínculo acarretava.

${ }^{5}$ De acordo com Pino (1991), os sistemas sinaléticos referem-se ao aparato responsável pela "transmissão de informações" no mundo animal. A ritualização dos comportamentos sociais animais como os cerimoniais de acasalamento, os cerimoniais de triunfo ou os cerimoniais de apaziguamento (LORENZ, 1969, p. 68) - revela a eficiência comunicativa desses sistemas.
} 
Lorenz (1970) verificou que, embora não fossem universais em aves e mamíferos, vínculos fortes e persistentes constituíam a regra em numerosas espécies. Lorenz (1970) observou em algumas aves que, durante os primeiros dias de vida, desenvolviam-se vínculos intensos com uma figura de ligação, sem nenhuma referência à alimentação, simplesmente através da exposição do filhote à figura em questão, com a qual se familiarizou.

Algumas características do imprinting poderiam ser explicadas, portanto, pela tendência que o filhote de determinada espécie tem para responder seletivamente a padrões de estímulos particulares. Convém ressaltar, ainda, que o imprinting aparece como resultado da seleção natural, pelo fato de ter a importante função de permitir não apenas o vínculo social entre o filhote e a mãe - mesmo que esta não seja a mãe biológica - mas também de favorecer a reprodução sexual entre os membros da mesma espécie.

Harlow (1965), por sua vez, ao realizar experiências incessantemente renovadas e refinadas com filhotes de macacos rhesus, criados com bonecos como mães substitutas, demonstrou a predominância do contato (pelo calor) sobre as atividades ligadas a fome e observou os efeitos da perda da mãe, entre outros aspectos, ressaltando a força e a necessidade vital do vínculo. Um bebê macaco, afirmou Harlow (1965), irá agarrar-se a um boneco que não o alimenta, desde que esse boneco seja macio e confortável.

Essas investigações realizadas com bebês-macacos provaram que nem mesmo a necessidade do alimento era capaz de substituir a necessidade de segurança e bem-estar assegurados pelo contato com a mãe. Desse modo, o bem-estar obtido levava, por um lado, o recém-nascido a unir-se mais estreitamente ao corpo materno, e por outro, a mãe a agarrar-se ao seu pequeno, de tal maneira que a satisfação era reforçada duplamente. Sem contar que a procura desse contato era caracterizada pela força de uma emoção e por uma persistência quase incontrolável.

Em uma de suas experiências de isolamento total realizada com fềmeas rhesus que nunca haviam criado vínculos maternos, Harlow (1965) observou que ao tornarem-se mães por fecundação artificial, as fềmeas ignoravam o seu filhote, o brutalizavam ou, até mesmo, o matavam. A grande surpresa dessa pesquisa foi a de que o pequeno macaco, apesar do comportamento de sua mãe, não se deixava rejeitar, nem desencorajar pelos golpes que lhe eram conferidos: ele pendurava-se às costas da mãe e tentava estabelecer, insistentemente, o contato com o seu corpo. 
A partir dos estudos de Harlow (1965) e de Lorenz (1970), ficou provado que não só entre as aves, mas também entre os mamíferos, os filhotes criavam vínculos com uma figura de ligação, apesar de não serem alimentados por essa fonte.

Essas investigações mostram com conviç̧ão que a criança humana unese à mãe (ou ao seu substituto) por mecanismos análogos ou semelhantes aos que ocorrem no mundo animal, o que não significa uma redução do homem ao animal. Portanto, a partir das pesquisas realizadas pelo enfoque etológico, o modelo-animal, de uma vez por todas, inverteu o seu significado.

Segundo Zazzo (1974), esta descoberta toma amplitude no momento em que se verifica que a necessidade de criar vínculos não é um fenômeno único à nossa espécie, mas existe igualmente (como demonstraram nomeadamente os trabalhos de Harlow e Lorenz) em numerosos mamíferos e certos pássaros.

De acordo com Zazzo (1974), compreende-se hoje que a oposição radical entre $o$ animal e o homem, é falsa. Tanto para um como para o outro, existem sistemas inatos cuja ativação opera-se em certos períodos críticos, e o fenômeno do vínculo é um destes sistemas.

Bowlby (1990), por sua vez, ao delinear uma teoria do vínculo num ensaio publicado em 1958, teve como quadro de referência no início de seus trabalhos uma perspectiva psicanalítica. Entretanto, ao distanciar-se nítida e progressivamente das primeiras teses da psicanálise, passou a argumentar que os dados empíricos sobre o desenvolvimento do vínculo de um bebê humano com sua mãe podiam ser melhor entendidos em termos de um modelo derivado da etologia. ${ }^{6}$

De acordo com Bowlby (2001, p. 158), em numerosos experimentos realizados com macacos jovens que foram separados da mãe, usualmente por cerca de uma semana, observou-se que na maioria das espécies de macacos estudados o protesto pela separação e a depressão durante a mesma eram pronunciados e, após a reunião, o apego à mãe era muito maior.

É certo que os tipos de vínculos que são formados diferem de uma espécie para outra, sendo mais comuns aqueles que existem entre os pais e sua prole, e entre adultos de sexos opostos. É certo também que nos mamíferos, incluindo os primatas, o primeiro e mais persistente de todos os vínculos é geralmente o que ocorre entre a mãe e seu filho pequeno,

\footnotetext{
${ }^{6}$ Convém assinalar que Bowlby (2001), em princípio, procurou uma conciliação entre a Psicanálise e a Etologia, mas acabou sendo expulso da Sociedade de Psicanálise por heterodoxia. $\mathrm{O}$ aspecto essencial da ruptura com esta corrente estava ligado à teoria do instinto postulada por Freud.
} 
A natureza do vínculo na vida humana

Sheila Daniela Medeiros dos Santos

um vínculo que frequentemente persiste até a idade adulta. No entanto, o que mais impressionou, de imediato, nesses experimentos foi a semelhança entre a resposta dos macacos e a dos seres humanos que vivenciaram a perda ou a separação da mãe.

Posteriormente, Bowlby (1990, p. 155) também descobriu que o alimento desempenhava apenas um papel secundário no comportamento de ligação de uma criança à mãe, e que esse comportamento se manifestava com o máximo vigor durante o segundo e o terceiro anos de vida e persistia com menos intensidade indefinidamente.

Portanto, embora os estudos de Bowlby (1990) e de Harlow (1965) tivessem sido desenvolvidos na mesma época de modo independente com base na observação empírica, ambos chegaram à mesma conclusão: a de que a necessidade de criar vínculos, de se ligar a outro membro da mesma espécie, tem um valor de sobrevivência tão grande quanto a necessidade de se alimentar.

Na teoria de Bowlby (1990), o vínculo surge como uma realidade instintiva que leva a criança a procurar manter uma situação de proximidade em relação à mãe. Se tal proximidade não é possível, a criança experiencia medo e insegurança. Essa tensão somente se reduz e desaparece quando outras situações de proximidade são (re)criadas com a mãe, a partir da procura do contato corporal ou da solicitação do colo materno.

Segundo Bowlby (1990), há fatores que interagem e são suscetíveis de ativar o instinto de vinculação ou aumentar a sua intensidade, tais como: as condições internas da criança (fadiga, fome, dor), a localização e resposta da mãe e as características ambientais.

Com efeito, apesar da propensão dos seres humanos a estabelecerem fortes vínculos com outros seres da mesma espécie ser evidente durante os primeiros anos da infância, Bowlby (1990) sustenta que tal comportamento caracteriza os seres humanos durante toda a sua vida:

[O vínculo] inclui o choro e o chamamento, que suscitam cuidados e desvelos, o seguimento e o apego, e também os vigorosos protestos se uma criança ficar sozinha ou na companhia de estranhos. Com a idade, a frequência e intensidade com que esse comportamento se manifesta diminuem gradativamente. No entanto, 


\section{HüMANAS}

todas essas formas de comportamento persistem como parte importante do equipamento comportamental do homem. Nos adultos, elas são especialmente evidentes quando uma pessoa está consternada, doente ou assustada. Os padrões de comportamento de ligação manifestados por um indivíduo dependem em parte, de sua idade atual, sexo, e circunstâncias, e, em parte, das experiências que teve com figuras de ligação nos primeiros anos de sua vida (BOWLBY, 1990, p. 171).

A partir desses dizeres, é possível delinear alguns aspectos que caracterizam a teoria do vínculo formulada por Bowlby (2001): a especificidade, refere-se à criação de vínculos com indivíduos específicos, geralmente em ordem de preferência; a duração, relaciona-se à durabilidade e persistência do vínculo em grande parte do ciclo vital; o envolvimento emocional, diz respeito à existência de emoções intensas que surgem durante a criação, a renovação e o rompimento dos vínculos; a ontogenia, faz alusão aos vínculos que se desenvolvem nos primeiros meses de vida do bebê; a aprendizagem, relaciona-se à possibilidade do bebê distinguir o familiar do estranho durante o processo de criação e desenvolvimento do vínculo; a organização, diz respeito à criação do vínculo mediado por respostas organizadas que partem de sistemas comportamentais simples até chegar àqueles mais refinados devido sua incorporação aos modelos representacionais; e, por último, a função biológica, a qual sugere que a criação do vínculo possui um valor de sobrevivência.

Essa discussão torna-se particularmente relevante, uma vez que Bowlby, ao abordar aspectos mais gerais ou mais específicos da temática, que se entrecruzam de diversas formas na sua interlocução com a teoria, reconhece que enquanto os teóricos da aprendizagem ignoram as tendências inatas, afirmando que a criação e o desenvolvimento do vínculo podem ser inteiramente explicados em termos de condicionamento operante, os psicanalistas insistem em não abandonar a teoria do impulso secundário que vincula o bebê à mãe. O que a análise de Bowlby não explica, porém, nem era a sua finalidade, é o papel da cultura, enquanto produção humana (VIGOTSKI, 1997), na criação do vínculo. 
Desse modo, apesar das idéias dos teóricos citados até o momento contribuírem com significativas parcelas e subsídios na busca de um instrumento interpretativo para a compreensão coerente acerca do vínculo, éna perspectiva histórico-cultural em Psicologia, que se torna possível compreender que a necessidade de criar vínculos, não deve ser pensada apenas em termos biológicos, mas deve ser pensada principalmente em termos de relações sociais, evocadas na/pela cultura. Nesse sentido, é por sua singularidade que essa perspectiva teórica marca lugar entre as produções sobre o fenômeno do vínculo.

Portanto, o que acreditava-se até então ser resultado de uma aprendizagem, agora passa a ser o efeito de uma necessidade primária tão imperiosa quanto a fome e que, para realizar-se dispõe provavelmente de mecanismos inatos que necessitam da cultura para desenvolver-se.

Zazzo (1989) constatou que o lactente, incapaz de agarrar-se à mãe como faz o pequeno rhesus ou de correr atrás da figura materna como faz algumas aves, recorre ao sorriso para instituir o vínculo. Segundo Zazzo (1989, p. 31), "os prelúdios do sorriso aparecem algumas horas após o nascimento", sendo que os primeiros sorrisos significativos, aqueles socializados, estão presentes aproximadamente a partir da terceira semana de vida.

Nesta mesma direção, Wallon (1968) afirma que o sorriso do bebê é um movimento expressivo com forte poder de mobilizar o meio que o circunda afetando o outro para atender às suas necessidades primordiais, sem o qual ele pereceria. Assim, dado o estado de imperícia inicial, o bebê apela ao outro para garantir os cuidados necessários à sua sobrevivência e para criar o vínculo social, instituindo o diálogo tônico-corporal com a mãe (ou seu substituto). Portanto, há uma tendência permanente do ser humano criar vínculos e manter relações com o outro. Nesse sentido, o sorriso pertence ao mesmo tempo tanto à ordem da afetividade, quanto à ordem da cognição, atuando com um duplo papel: o orgânico e o social.

Como esse trabalho se situa na perspectiva histórico-cultural em Psicologia, conforme Pino (2005) bem observou, ao considerar que é com a mãe (ou seu substituto) que a criança tem as primeiras experiências de relação ${ }^{7}$,

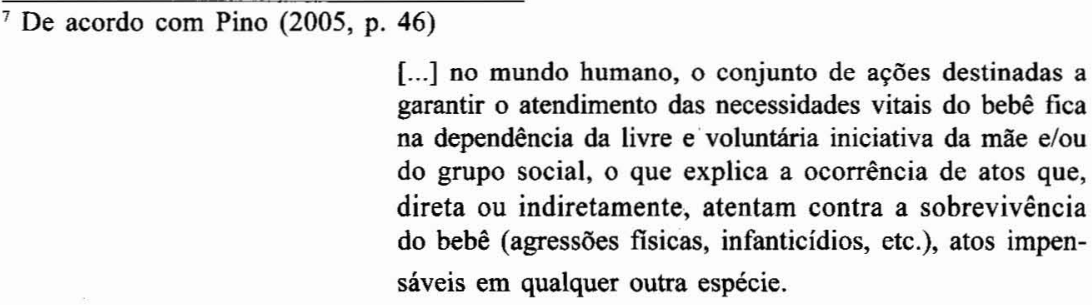

[...] no mundo humano, o conjunto de ações destinadas a garantir o atendimento das necessidades vitais do bebê fica na dependência da livre e voluntária iniciativa da mãe e/ou do grupo social, o que explica a ocorrência de atos que, direta ou indiretamente, atentam contra a sobrevivência do bebê (agressões físicas, infanticídios, etc.), atos impensáveis em qualquer outra espécie. 
e que essa relação, mediada pela linguagem, ocorre num contexto histórico e cultural determinado, pode-se dizer que a criança, ao nascer, é capturada por uma multiplicidade de relações sociais que faz com que a sua dimensão orgânica seja impregnada pela cultura e marcada pela história. Nesse sentido, de acordo com Vigotski (1995), o desenvolvimento psíquico da criança se produz entrelaçado ao desenvolvimento histórico da humanidade.

Chegando a este ponto do processo de investigação, convém ressaltar: se na perspectiva histórico-cultural em Psicologia as funções biológicas sãoo substrato sob as quais se constroem as funções sociais, e se o vínculo é uma função básica, biológica sob a qual se constitui a sociabilidade humana, então pode-se afirmar que as relações sociais se sustentam numa sociabilidade cuja base é a necessidade de criar vínculos.

\section{O movimento da sociabilidade anima/humana}

Trazendo as reflexões empreendidas até o momento para o campo do assunto que ocupa este trabalho, pode-se dizer, em síntese, que o homem é um ser social por natureza (WALLON, 1968), pelo fato de estar ligado à existência do outro e de manifestar uma necessidade vital de complementaridade. Em outros termos, há uma natureza biológica da sociabilidade que só pode ser entendida a partir do processo de conversão das funções biológicas em funções simbólicas, uma vez que as funções culturais, de origem social, exigem o suporte biológico para se constituírem em funções da pessoa.

Todavia, as noções de vinculação e de sociabilidade dentro desse eixo de análise não devem ser confundidas. Na verdade esta seria uma armadilha etimológica. Em relação a esse aspecto, Pino (2000) afirma:

[...] tanto no mundo animal quanto no mundo humano, o social é um "valor agregado" ao biológico, qualquer que seja a maneira como ele emerge. Isso quer dizer que, se o biológico constitui o substrato de toda forma de sociabilidade, não constitui, porém, causa suficiente para a sua emergência, relacionada às diferentes formas de adaptação de determinadas espécies de organismos às condiç̋̃es de existência nos seus respectivos meio ecológicos - formas de adaptação que evoluem em função das mudanças que ocorrem nessas condições de existência (PINO, 2000, p. 60). 
Como no mundo animal existem formas variadas de organização social, muitas delas próximas das criadas pelo homem, na lógica do princípio evolutivo é possível afirmar que a sociabilidade animal é o substrato da sociabilidade humana, do mesmo modo que a natureza é a condição de emergência da cultura.

Entretanto, se do ponto de vista metodológico nos apoiamos em um modelo teórico que prioriza a relação dialética entre as funções básicas e as funções culturais, convém ressaltar que a função cultural jamais poderá substituir uma função básica; afinal, nenhum tipo de relação interpessoal substitui aquela relação básica que é sentir que o outro o reconhece enquanto espécie, seja quem for. Isso quer dizer que não se pode construir uma sociabilidade em cima de princípios abstratos, metafísicos.

Sendo assim, é possível às outras espécies animais diferentes da humana emitir e captar sinais (visuais, sonoros, olfativos) que lhes permitem orientar suas ações, realizar escolhas de parceiros, e compartilhar emoções que lhes dão a possibilidade de interagir com o meio físico do qual fazem parte, bem como com os seus congêneres.

Embora esses sistemas sinaléticos sejam considerados altamente especializados no mundo animal, o que faz da sinalização, de acordo com Pino (2000), a base mais geral das condutas animais, no mundo dos homens tais sistemas são insuficientes e inaceitáveis, devido ao caráter fixo e imutável que adquirem no contexto cultural.

Desse modo, como a sociabilidade humana se concretiza numa estrutura de relações que são estruturas de reconhecimento, por mais que as primeiras relações que ocorrem no mundo dos homens sejam semelhantes às que ocorrem no mundo animal, tais relações não serão simplesmente relações de contato, pois no mundo dos homens há reconhecimento dentro das características que constituem a sociabilidade humana. Portanto, contrariamente ao que ocorre no mundo biológico, a sociabilidade humana não é simplesmente dada pela natureza, mas é assumida pelo homem que procura formas variadas de concretizá-la a partir dos processos de significação.

Numa de suas obras, Wallon (1995) afirma que através de sinais, os indivíduos identificam e reconhecem quem é o outro, se ele é estranho ou se ele é familiar, se ele pode se aproximar desse outro ou não. Mas, para isso, os indivíduos conferem a essas funções uma significação, atribuindo às atividades biológicas uma dimensão simbólica. No campo humano, para ultrapassar esse tipo de sociabilidade são instituídas as relações sociais. 
Segundo Zazzo (1989), mesmo se for estabelecido que as sociedades humanas possuem as mesmas estruturas elementares que certas sociedades animais, mesmo se for confirmado que a lógica da vida e a lógica dos grupos humanos são idênticas, continuaria a ser evidente que qualquer sociedade, que qualquer grupo humano, seria capaz de extrapolar e transcender o plano biológico, inscrevendo-se no plano cultural, uma vez que o homem é produtor do real.

Não obstante, o perigo principal de tal argumento é a tendência de reduzir o comportamento humano aos "modelos animais", aos mais simples destes modelos, considerando como semelhança o que é apenas analogia. Não podemos nos esquecer que a comparação exige a investigação tanto das diferenças quanto das semelhanças, para que tal comparação seja válida e realmente explicativa.

Nessa linha de raciocínio, a emergência do social humano, diferente das formas animais de sociabilidade, tem de ser explicada por princípios outros, e não os meramente naturais ou biológicos:

As formas humanas de organização social, em que a sociabilidade natural se concretiza, são obras do homem e, como tal, obedecem a leis históricas que determinam as condições concretas de sua produção. É o caráter histórico dessa produção que define o social humano (PINO, 2000, p. 61).

A partir dessas considerações teóricas, o problema fundamental que se coloca é saber quais processos e em quais condições, o vínculo dá origem à sociabilidade. Nesse momento, o termo vínculo nos conduz a uma questão do mesmo modo essencial: como conceber a passagem do biológico ao cultural?

É a dificuldade de resolver este enigma que obstrui a teoria psicológica e que, ainda nos dias de hoje, deixa o campo científico livre a inúmeros pontos obscuros e às mais diversas imposições.

Contudo, é Lev S. Vigotski, principal teórico da vertente históricocultural, quem introduz na história do pensamento psicológico a análise do processo de transformação de um ser biológico em um ser cultural ${ }^{8}$.

${ }^{8}$ Embora a realidade biológica e a realidade cultural pertençam a ordens bem diferentes, pelo fato de possuírem propriedades diversas e forças que se opõem, podemos dizer que essas duas dimensőes constituem um par inseparável e compõem "uma unidade de contrários" na história humana. Em outras palavras, uma pressupõe a outra para que ocorra a emergência do homem como ser humano. 
Pino (2000, p. 65), a partir da leitura dos trabalhos desse autor, enfatiza que o desenvolvimento cultural passa por três momentos: o desenvolvimento em si, para os outros e para si. Em relação a esse aspecto, diz ele:

O primeiro momento é constituído pelo dado em si, realidade natural ou biológica da criança enquanto algo que está dado. É o momento teórico que precede à emergência do estado de cultura. $\mathrm{O}$ segundo momento é aquele em que o dado em si adquire significação para os outros [...]. É o momento histórico da emergência do estado de cultura; momento de distanciamento do homem da realidade em si, a qual se desdobra nele na forma de representação, testemunhando a presença da consciência. Enfim, o terceiro momento é aquele em que a significação que os outros atribuem ao dado natural se torna significativo para si, ou seja, para o indivíduo singular. É o momento da constituição cultural do indivíduo quando, através desse outro, ele internaliza a significação do mundo transformado pela atividade produtiva, o que chamamos de mundo cultural. Portanto, o desenvolvimento cultural é o processo pelo qual o mundo adquire significação para o indivíduo, tornando-se um ser cultural (PINO, 2000, p. 65-66, grifos do autor).

Uma hipótese científica que se torna cada vez mais incontestável referese ao fato de que a cultura sela o patrimônio genético que cada ser humano singular e concreto herda de seus antepassados. Com efeito, antes mesmo de ocorrer a inserção do "possível candidato à humanidade" (PINO, 2005, p. 58) no mundo dos homens, diferentes mecanismos culturais entram em ação, fazendo com que o mesmo fique atrelado às condições reais de existência e de nossa história social.

De fato, há um caráter indissociável do biológico e do social na natureza humana: as inaptidões do recém-nascido, que poderiam ser vistas como uma debilidade física e um obstáculo ao seu desenvolvimento, na verdade não o são. 


\section{HÜMANAS}

Isso porque essas inaptidões sofrerão profundas transformações e serão superadas pelo contato com o mundo social, de tal forma que o recém-nascido possa beneficiar-se da experiência cultural da espécie humana para tornar-se um ser humano. Em outras palavras, o estado de imperícia inicial, confere ao ser humano uma dimensão social que é a condição de sua superioridade sobre as outras espécies animais. O corpo, ainda imaturo fisiologicamente, busca no social o seu complemento. ${ }^{9}$

Estas proposições nos remetem a mais uma afirmação proficua de Vigotski $(1994,1995,1996)$ : a de que a criança passa de um estado meramente biológico ao estatuto de um ser cultural à medida que se estabelecem progressivamente as primeiras relações sociais.

Desse modo, considerando que o outro é um ser imprescindível para a realização das relações sociais e que estas, por sua vez, são constitutivas da pessoa, fica evidente que a necessidade de criar vínculos não pode ser explicada apenas no mundo animal, uma vez que é essa mesma necessidade, imersa no mundo simbólico ou da significação, que leva a sociabilidade humana.

Segundo Pino (2000), como o social é um fenômeno inextricável à cultura, por ser um dos atributos de certas formas de vida, é possível falarmos de uma sociabilidade biológica, natural, que sob a ação criadora do homem, é capaz de adquirir formas humanas novas de existência, tornandose modos de organização das relações sociais dos homens.

Neste sentido, o social é, ao mesmo tempo, condição e resultado do aparecimento da cultura. É condição porque sem essa sociabilidade natural a sociabilidade humana seria historicamente impossível e a emergência da cultura seria impensável.É, porém, resultado porque as formas humanas de sociabilidade são produções do homem, portanto obras culturais (PINO, 2000, p. 53).

Dessa maneira, a necessidade de criar vínculos instaura um ponto de intersecção entre estes dois campos, a sociabilidade biológica e a sociabilidade humana, pois se não houvesse a necessidade de criar vínculos, não haveria relações sociais, do mesmo modo que, se não houvesse relações sociais não haveria como o vínculo se instituir.

${ }^{9}$ De acordo com Zazzo $(1989$, p. 95$)$ nossa sobrevivência supõe a sociabilidade. 
Segundo Vigotski (1996), como as relações sociais entre as pessoas dão origem às funções psicológicas superiores, a natureza psicológica dos homens representa o agregado de relações sociais internalizadas que se tornaram para o indivíduo funções e formas da sua estrutura. ${ }^{10}$

De acordo com esse autor, as mudanças que ocorrem nesse processo não se referem precisamente a estas funções, nem à sua estrutura, mas ao nexo destas funções entre si, de maneira que surgem novos agrupamentos desconhecidos no nível precedente. Nesse sentido, Vigotski (1996) afirma:

Não se trata de que as alterações se dêem exclusivamente no seio das funções, mas de que existem alterações nas conexões e na infinita diversidade de formas destas se manifestarem; que em uma determinada fase de desenvolvimento aparecem novas sínteses, novas funções cruciais, novas formas de conexões (VIGOTSKI, 1996, p. 135).

À luz de todos esses elementos analisados, e tendo em conta que a tese das relações sociais, proposta por Marx e Engels e formulada por Vigotski, envolve dois planos distintos, porém inextricáveis: o plano estrutural da organização social, com suas dimensões políticas e econômicas, e o plano das relações pessoais entre os indivíduos concretos ${ }^{11}$, é possível depreender que se de um lado as relações sociais marcam a vida humana, de outro, a vida humana inevitavelmente imprime um sentido de dramaticidade às relações sociais.

Por fim, é particularmente interessante enfatizar que as tramas e as tessituras que compõem o cenário teórico desse trabalho não permitem uma conclusão definitiva, mas indubitavelmente indicam o surgimento de uma nova gama de questões e possibilidades para se compreender o fenômeno do vínculo na vida humana, fenômeno este que se situa na fronteira tênue e enigmática de dois mundos que se distinguem e, ao mesmo tempo, se entretecem: o mundo da natureza e o mundo da cultura. Eis o desafio que se abre.

\footnotetext{
${ }^{10}$ Lembrando o que disse Wallon (1968, p. 69): "toda recordação atua em nós sob a influência de nossa evolução psíquica, de nossas disposições e situações", é possível pensar o contrário, que toda evolução psíquica atua sob influência da recordação. Em outras palavras, a evolução psiquica só opera dentro desta condição: a de recordar/(re)viver as relações sociais (antes de serem convertidas em funções) para que a criança possa conferir uma significação às suas novas relações com as coisas e com as pessoas e, deste modo, possa convertê-las em funções psicológicas.

$"$ De acordo com Pino (2000, p. 64), "dado que as relações sociais são determinadas pelo modo de produção da sociedade, as posições sociais e os papéis a elas associados traduzem a maneira como as forças produtivas se configuram nessa sociedade".
} 


\section{Referências bibliográficas}

AINSWORTH, M. D. Privacion de los cuidados maternos: revision de sus consecuencias. Genebra: OMS, 1963.

BINET, A.; SIMON, T. Testes para a medida do desenvolvimento da inteligência. São Paulo: Melhoramentos, 1929.

BOWLBY, J. Formação e rompimento dos vínculos afetivos. 3. ed. São Paulo: Martins Fontes, 2001.

BOWLBY, J. Apego: a natureza do vínculo. 2. ed. São Paulo: Martins Fontes, 1990 , v. 1.

FREUD, S. Três ensaios sobre a teoria da sexualidade. Rio de Janeiro : Imago, 2002.

FREUD, S. Além do princípio do prazer. Rio de Janeiro: Imago, 1998.

GESELL, A. L. A criança dos 0 aos 5 anos. São Paulo: Martins Fontes, 1992.

HARLOW, H. F. Behavior of nonhuman primates: modern research trends. New York: Academic, 1965.

KLEIN, M. Novas tendências na psicanálise. Rio de Janeiro: Zahar, 1969.

LORENZ, K. Os fundamentos da etologia. São Paulo: Unesp, 1995.

LORENZ, K. Trois éssais sur lê comportement animal et humain: les leçons de l'evolution de la theorie du comportement. Paris: Ed. Du Seuil, 1970.

PIAGET,J.Onascimento da inteligência na criança. Rio de Janeiro:Zahar, 1975.

PIAGET, J. A formação do simbolo na criança. Imitação, jogo e sonho, imagem e representação. Rio de Janeiro: Zahar, 1971.

PIAGET, J. A construção do real na criança. Rio de Janeiro: Zahar, 1970.

PINO, A. As marcas do humano: às origens da constituição cultural da criança na perspectiva de Lev S. Vigotski. São Paulo: Cortez, 2005.

PINO, A. O social e o cultural na obra de Lev S. Vigotski. Vigotski - O manuscrito de 1929. Tema sobre a constituição cultural do homem. Educação e Sociedade, 2. ed. Campinas-SP, n. 71, p. 45-78, out. 2000. 
A natureza do vínculo na vida humana

Sheila Daniela Medeiros dos Santos

PINO, A. O conceito de mediação semiótica em Vygotsky e seu papel na explicação do psiquismo humano. Pensamento e linguagem - estudos na perspectiva da psicologia soviética. Caderno Cedes. 3. ed. Campinas-SP, n. 24, p. 38-51, jul. 2000.

SCHAFFER, H. R. The child's entry into a social world. London; Orlando: Academic Press, 1984.

SEARS, R. R. et al. (org.) As 7 idades do homem: um estudo do desenvolvimento humano: corpo, personalidade, capacidades. Rio de Janeiro: Zahar, 1975.

SKINNER, B. F. Ciência e comportamento humano. São Paulo: Martins Fontes, 1989.

SKINNER, B. F. Sobre o behaviorismo. São Paulo: Cultrix, 1985.

SPITZ, R. O primeiro ano de vida. São Paulo: Martins Fontes, 1996.

VIGOTSKI, L. S. Psicologia pedagógica. São Paulo: Martins Fontes: 2001.

VIGOTSKI, L. S. The collected works. New York: Plenun Press, v. 5, 1997.

VIGOTSKI, L. S. Teoria e método em psicologia. São Paulo: Martins Fontes, 1996.

VIGOTSKI, L. S. Pensamento e linguagem. São Paulo: Martins Fontes, 1995.

VIGOTSKI, L. S. A formação social da mente. São Paulo: Martins Fontes, 1994.

WALLON, H. As origens do caráter na criança. São Paulo: Nova Alexandria, 1995.

WALLON, H. Do acto ao pensamento: ensaio de psicologia comparada. Lisboa: Moraes, 1979.

WALLON, H. A evolução psicológica da criança. Lisboa: Persona, 1968.

WINNICOTT, D. W. $O$ ambiente e os processos de maturação: estudos sobre a teoria do desenvolvimento emocional. PortoAlegre: Artes Médicas, 1990.

ZAZZO, R. Onde está a psicologia da criança? Campinas, SP: Papirus, 1989. 